\title{
Justification of Emotional and Instrumental Aggression in Hong Kong and Spanish University Students
}

\author{
J. Martín Ramírez ${ }^{1, *}$, Annis Lai-chu Fung ${ }^{2}$, Jesus M. Alvarado ${ }^{3}$ and Luis Millana ${ }^{1}$ \\ ${ }^{l}$ Psychobiology Department \& Institute for Biofunctional Studies, Universidad Complutense Madrid \\ ${ }^{2}$ Department of Applied Social Studies, College of Liberal Arts and Social Sciences, City University of Hong Kong \\ ${ }^{3}$ Department of Methodology of Behavioral Sciences \& Institute for Biofunctional Studies, Universidad Complutense Madrid
}

\begin{abstract}
This study reports the degrees of approval for different aggressive acts in a number of instrumental and emotional situations. A nationally-adapted version of the Lagerspetz and Westman questionnaire [1] was administered to 332 university students of both sexes in Spain and Hong Kong. Respondents had to indicate levels of justification of several aggressive acts of different quality and intensity in the context of different social justifications. Our results replicated the general findings of previous research in other cultures: in both samples, more drastic forms of aggression (e.g., killing, torture) were less accepted than non-dangerous forms of such behavior (e.g., hindering, being ironic); aggressive acts more socially justified (in terms of protection of self or other) were clearly more accepted than others with no such justification (problems of communication); and instrumental-motivated aggression was higher justified than emotional-motivated aggression. Some differences in the level of acceptance according to the sex of the participants were found: women were more prone to a higher acceptance of acts and situations more related to emotion. Although both sexes justified aggression in a higher degree for instrumentally motivated situations than for emotional ones, males showed a higher acceptance than females for instrumental situations and a lower one than females for emotional ones. There were also some minor culturally bound differences in these attitudes: Spaniards accepted less than HK students aggression in emotional situations, specially for the cases of punishment and lack of communication, but more emotional acts, such as rage and shouting. Thus, patterns of moral approval of various kinds of aggressive acts are in a large part common to both cultures. Findings also confirmed a two-factor solution and the respective predictive power of justifications for aggression in instrumental vs. emotional motivated situations. The reliability and validity of this brief self-report have been further established by the present study, paving the way for future studies to measure instrumental and emotional aggression.
\end{abstract}

Keywords: Aggression, Hong Kong, Spain, attitudes.

\section{INTRODUCTION}

Far from being an unequivocal, one-dimensional term, aggression is a heterogeneous and complex phenomenon with substantial semantic overlap with terms for many different forms of behaviour categorised by the intention to harm others [2]. This implies that it is not enough to agree on a general definition without first establishing the existence of specific functional types of aggression, each with different regulatory mechanisms and determinants [3]. The analysis of the attitude toward different kinds of aggression offers an important perspective that sheds light on a better understanding of the intrinsic motivation of aggressive acts. For instance, a distinction can be made between hostile or emotional aggression (based simply on the pleasure of causing harm or on an impulsive feeling) and instrumental aggression (aimed at achieving non-aggressive goals) [4- 6]. Other classifications distinguish between reactive and proactive aggression [7,8] or between impulsive and premeditated aggression [9-11]. A statistical analysis of

*Address correspondence to this author at the Psychobiology Department \& Institute for Biofunctional Studies, Universidad Complutense Madrid; Tel: 34918444 695; Fax: 34913943 069; E-mail: mramirez@med.ucm.es empirical data in our laboratory revealed a significant link between instrumental, proactive and premeditated aggression, on the one hand, and hostile, reactive and impulsive aggression, on the other [12]. The first sociocognitive type of aggression is often seen in a positive light due to its instrumental-premeditated-proactive-controlledcalculated-offensive-predatory-in cold blood focus associated with a positive view of aggression, whereas a second type is often viewed negatively due to its hostile-impulsive-reactiveuncontrolled-retaliatory-defensive-emotional-hot blooded emphasis [13].

The extent that a person justifies aggression is based on an interaction of physiological and psycosocial factors, from biology and personality traits to aspects of lifestyle, such as choice of profession, attitude toward life, the Weltanschaaung and prevailing societal norms [14-16].

The present study sought to clarify the personal degree of approval of different aggressive acts in various instrumental and emotional-motivated situations, by people from two quite different cultures, in the understanding that a finer discrimination in the conceptualization of aggression could contribute to refine preventive, therapeutic, and policy interventions aimed at reducing aggression. 
We expected the results to mirror past findings in different cultures from several continents [17-25]. To a large extent their justification would correspond to universal rules, based on common sense and embedded in our human biology: mild acts, such as verbal aggression, would be more acceptable than stronger ones involving physical aggression; gross provocation would permit greater approval than unprovoked aggression; and people would be more likely to approve acts motivated by altruism than those by selfishness.

However, norms, values, and beliefs about the morality of particular aggressive acts might vary by culture as well as by specific circumstances [26]. Some differences in culture may be linked to differences in the way the self is construed as well as in societal regulations. Markus and Kitayama [27, 28] pointed out that there are cross-cultural differences in the construals of the self, of others, and of the interdependence between the self and others; and that they have a set of specific consequences for cognition, emotion and motivation. Europeans typically have an independent view of the self and seek independence from others. The prototype of a western society is independence, autonomy, and free spirit, with the primacy of the individual as its kernel value [29]. On the contrary, Asian cultures have an interdependent construal of the self, they are socially oriented, and they are concerned with fitting in, belonging, promoting other's goals and being indirect. Consequently, findings from Spain, a WEIRD (Western, Educated, Industrialized, Rich and Democratic) society, following the known acronym [30], a member of the European Union, may not generalize across other cultural contexts, such as Hong Kong, a former British colony in Asia, from 1843 to $1997^{1}$. Both are diverse on several sociodemographic dimensions, including predominant religion, economic indicators, and indices of child well-being, as well as psychological characteristics such as individualism and collectivism.

Although Markus and Kitayama did not examine the consequences of their theory on aggression, these differences are expected to affect aggression too: Asians may be more repressed compared to Westerners. Hofstede's individualism vs collectivism theory [33, 34] would also lead to the prediction that Asians would show a lower justification of aggression, because in high uncertainty avoidance cultures, aggressive behavior of the self and others is acceptable; however, individuals prefer to contain aggression by avoiding conflict and competition [35]. A recent study with Chinese adolescents showed collectivism negatively related to their aggression, while individualism was positively related to it [36].

Some eventual differences inherent to each sex, have already been described in the literature on aggression. Even if both sexes may be equally aggressive, they tend to express it in different ways [37, 38]: males tend to be more direct

\footnotetext{
${ }^{1}$ Sociological studies assure us that powerful bicultural influences are present in many aspects of its societal level, which promote acculturation on individual psychological levels [31] Despite English being the official language in government and schools, Chinese language and Chinese history, taught in Chinese, are required in schools. Street names and announcements on public transits are bilingual. Furthermore, Buddhist temples and Christian churches, as well as architecture in traditional Chinese and British styles, are cultural symbols commonly seen in daily life. Societal progression in Hong Kong is the result of inseparable bicultural contributions and its democratic infrastructure allows all traditions to flourish, regardless of their Chinese or western origins [32].
}

physically aggressive, females are more direct non-verbally aggressive, whereas no sex differences are usually found on indirect aggression, i.e. aggressors hide their identities [3942]. These psychobiological characteristics allude to similar male and female tendencies in instrumental and emotionalmotivated aggression across cultures? [26].

Thus, based on the abovementioned arguments, the following hypothesis were proposed: $\mathrm{H}_{1}$ the degree of acceptance of aggression is by and at large common to all human beings, $\mathrm{H}_{1 \mathrm{a}}$ a similar trend in the personal degree of approval of the different acts during particular circumstances would be predicted for these two cultures, with a lower justification of the more serious forms of aggression than mild ones, and $\mathrm{H}_{1 b}$ a higher willingness of instrumental aggression than of hostile or emotional aggression would also be expected [43]. $\mathrm{H}_{2}$ Congruent with the aforementioned $\mathrm{H}_{1}$, some minor characteristics peculiar to each cultural group would also be expected. $\mathrm{H}_{3}$ Even if both sexes may be equally aggressive, each might prefer a different expression [39] and, consequently, some sex differences would be observed.

For this purpose a brief self-report that reliably assesses the hostile/emotional-reactive and instrumental-proactive dichotomy of aggression [44, 45] was employed. Originally constructed by Lagerspetz and Westman [1] and subsequently revised by Ramirez [21] it is known by its Spanish initials CAMA (Cuestionario de Actitudes Morales sobre Agresión).

\section{METHODS}

\section{Participants}

Three hundred and thirty-two undergraduate students, with 219 females and 108 males between 18 and 26 years of age, participated in the present study. Our sample seemed to represent the indigenous population in Spain and Hong Kong. All had grown up in an urban environment and were natives of their country: 156 in Madrid (age $\mathrm{M}=20,56 \mathrm{SD}=$ 1,26 ) and 171 in Hong Kong (age $\mathrm{M}=20,89 \mathrm{SD}=2,06$ ). The data from students of non-Chinese or non-Spanish origin were excluded from the analysis, even if most of them were born or lived there for most of their lives.

\section{Questionnaire}

The CAMA questionnaire is a particularly appropriate instrument because it distinguishes between the two factors we wanted to study. Since the degree of approval would depend on the qualities of the behavior observed, its items describe different types of aggressive acts in combination with diverse situations in which they may be conducted. The eight categories of aggressive acts are: hitting (ht), killing (ki), shouting angrily (sh), being ironic (ir), using torture (to), having a fit of rage (ra), threatening (th) or hindering another person from doing something (hd). Each category of acts is accompanied by a list of six different circumstances in which the aggressive behavior may be justified, namely: in self-defense (SD), in protecting another person (DO), in defense of one's property (DP), as a consequence of emotional agitation (EM), as a punishment (PU), or as a way of overcoming communication difficulties (NC). 


\section{Procedure}

The survey was administered in classrooms and participation was on a volunteer basis. The average time taken to complete the self-report measures was approximately 15 minutes. The Madrid students answered to the questionnaire in Spanish, and the Hong Kong counterparts in Chinese, even if English is widely understood and spoken by more than onethird of the Hong Kong population. The scale was translated by a professional and the accuracy was verified by bilingual people.

Instructions were concise and simple, and in order to facilitate a non-defensive response style, they started with the acknowledgment that most people feel angry at times. Each positive answer to the justification of an act was scored with 1 point ("yes" = justified = 1), whereas the negative answer to the justification of an act was scored with 0 points ("no" = no justified $=0$ ). Mean scores were calculated so that a higher score indicated more justification (minimum value $=0 ;$ maximum value $=6$ for situations, and maximum value $=8$ for acts).

\section{Statistical Analysis}

Cronbach's Reliability Coefficient, Confirmatory Factor Analysis (CFA) and Repeated Measures Analysis of Variance (ANOVA) were applied to assess the data. Statistical analysis was carried out using SPSS 19 and Lisrel version 8.80. Tukey LSD post hoc comparisons between each act and between each situation were also done.

\section{RESULTS}

The internal consistency of the scale reported was a Cronbach's alpha coefficient of .84 for total sample. A confirmatory factorial analysis supported a significant fit for a bifactorial structure of the CAMA questionnaire, confirming a two-factor model. All items loaded significantly on their respective factors. In both samples: Goodness of Fit Index $(\mathrm{GFI})=0.95$ and Standardized RMR $=0.074$. Fig. (1) shows the existence of two factors, which correspond to instrumental and emotional motivations for aggression.

\section{Situations}

A repeated ANOVA was performed to determine the impact of two independent variables (country and sex) on the justification of aggression in the six different situations evaluated by the CAMA test. The differences between the situations were statistically significant: $\mathrm{F}(5,1615)=83.28$, $\mathrm{p}<0.001)$, while country and sex covariables were found to be statistically non-significant: $F(1,323)=0.869(p=0.352)$ for country; and $\mathrm{F}(1,323)=0,01(\mathrm{p}=0.989)$ for sex.

Fig. (2) shows a clear-cut difference between the degree of justification for instrumental factor (self-defense, defense of other people, and defense of property) and emotional factor (lack of communication, punishment and anger). Aggression was more justified for solving instrumental situations (3'8 from a maximum of 6 ) than for emotional ones (2'7 from 6).

Tukey LSD post hoc comparisons showed significant differences $(\mathrm{p}<0.02)$ between all pairs, except between self-

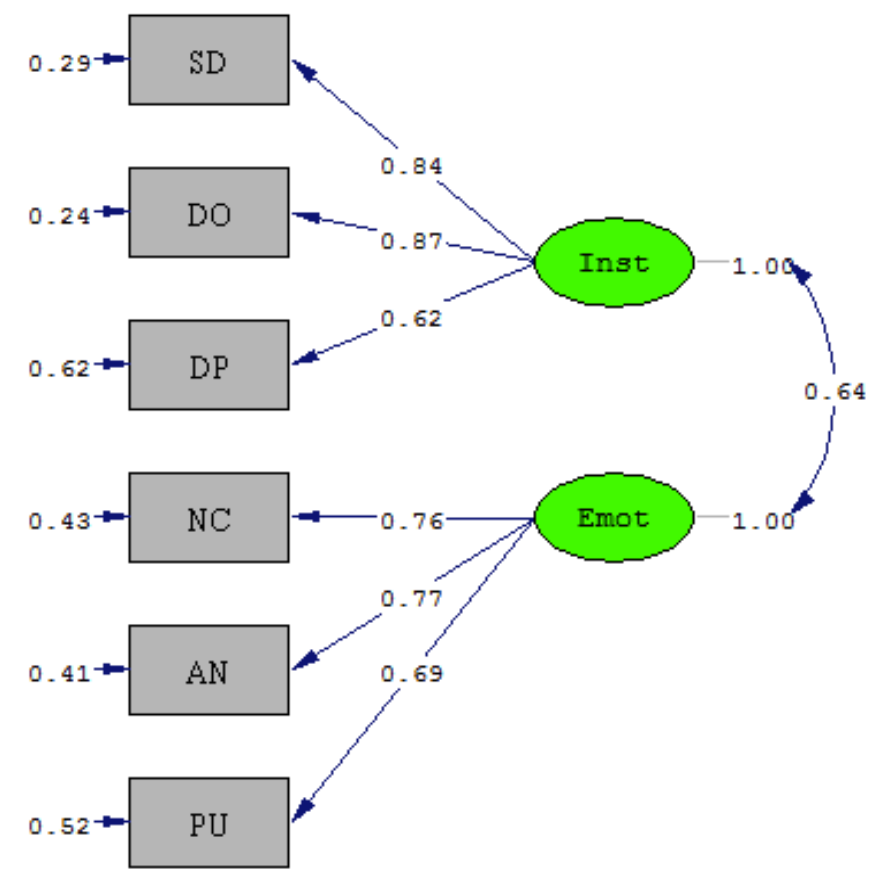

Fig. (1). Two-factor model.

defense and defense of property $(p=0.417)$ and between punishment and anger $(\mathrm{p}=0.684)$. Gross provocation led to a higher approval of retaliation than unprovoked aggression (e.g., killing was considered more justified for altruistic reasons than as a mere expression of bad temper). Socially justified aggressive acts, such as those conducted in protection of self or other, were clearly more accepted than ones with no such justification (e.g. as an expression of emotions, as a result of communication difficulties). Within the defensive situations, defending others and self defense received more moral approval than defending property did. On the other hand, punishment and emotional reaction had very low level of justification, and communication problems as circumstances for aggression action were seen as the least justified in both populations.

Another ANOVA showed Interactions between the justification of aggression in the different situations and countries $F(5,1615)=7.535(p<0.001)$, where the main effect of situation was significant and the main effect of country was not significant (Fig. 3). While there was a continuous and progressive slope along the different situations for the Hong Kong population, Spaniards showed a clearer difference across the two factors: their justification of aggression was lower for emotional situations (especially in the situations of punishment and because of lack of communication) than in instrumental situations.

Finally, no significant sex differences were observed (Fig. 4) -aggression was justified to a higher degree for instrumental situations than for emotional ones. Interactions between CAMA situations and sexes, however, were observed $F(5,1615)=4.681 \quad(p<0.001)$, with aggression justified in a higher degree in instrumental situations by men than by women, whereas that trend was inverted in emotional/hostile situations, with women justifying aggression in a higher degree than men did. 


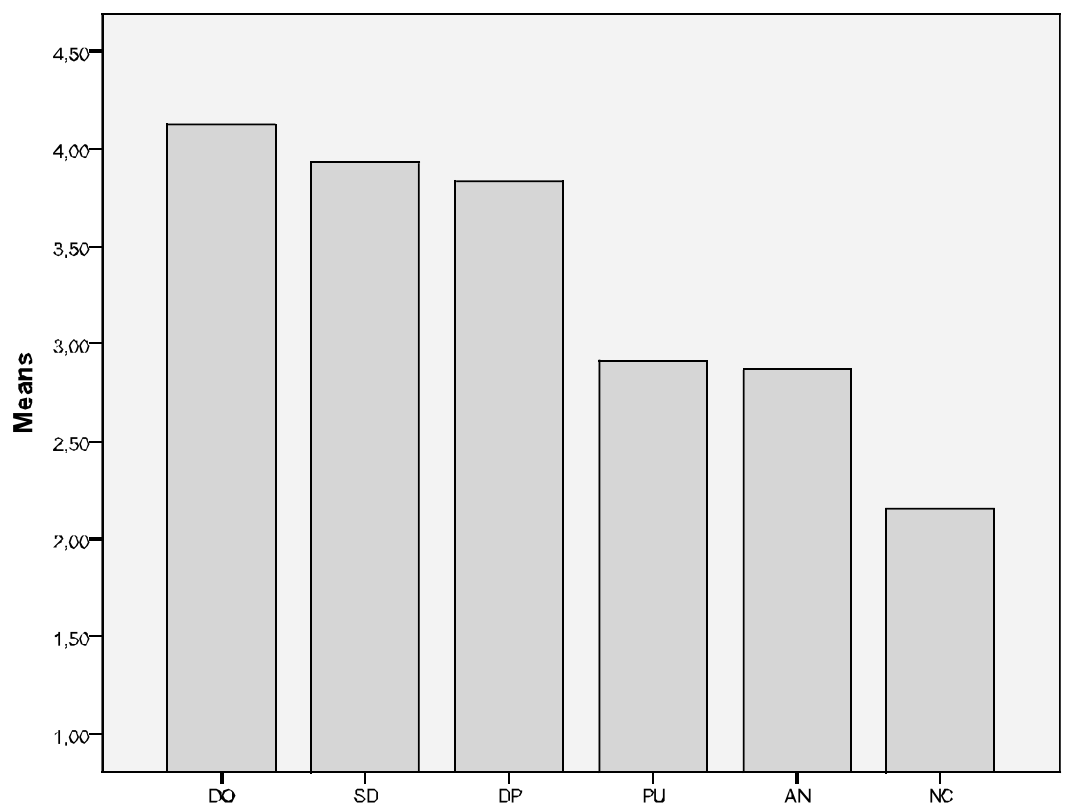

Fig. (2). Justification of aggression for each situation.

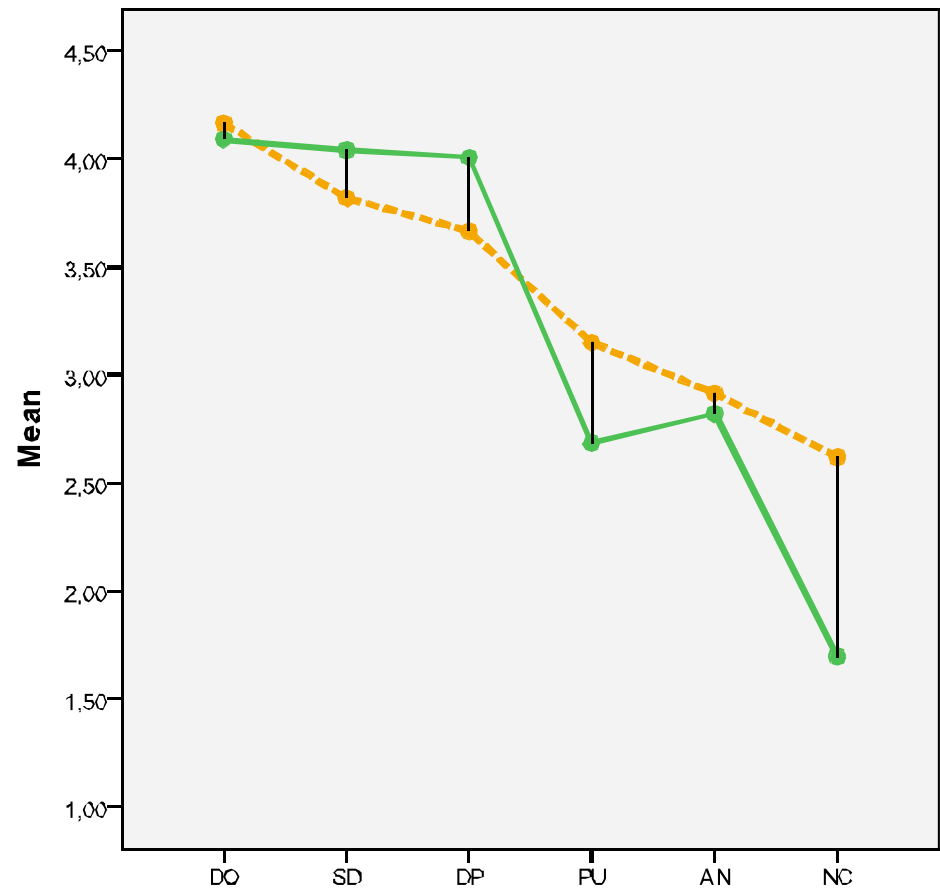

Fig. (3). Justification of aggression for each situation (discontinuous orange line = Hong Kong; continuous green line $=$ Spain).

\section{Aggressive Acts}

A second repeated ANOVA was performed to determine the effect of variables country and sex on the justification of aggression in the 8 acts included in the CAMA test. The ANOVA showed significant differences in the justification of different acts: $F(7,2261)=217,42(p<0.001)$ (Fig. 5). The mean scores for justification were around $70 \%$ for milder aggressive acts (ir, sh, and ra) and passive aggression (hd), which were much higher than the justification for more severe ones (th, ht, to, and ki).
ANOVA also showed a significant Interaction between the justification of different aggressive acts and countries $\mathrm{F}(7,2261)=8.540(\mathrm{p}<0.001)$, with non-significant differences between both countries. Although there was the same trend in both populations (the more severe were the aggressive acts, the less justified they were), Hong Kong students seemed to accept severe acts more than Spaniards, whereas, on the contrary, Spaniards were able to better justify mild aggression than Hong Kong students (Fig. 6). There were significant differences $(p<0.05)$ between both countries for each act, with the exception of sh, and hd. 


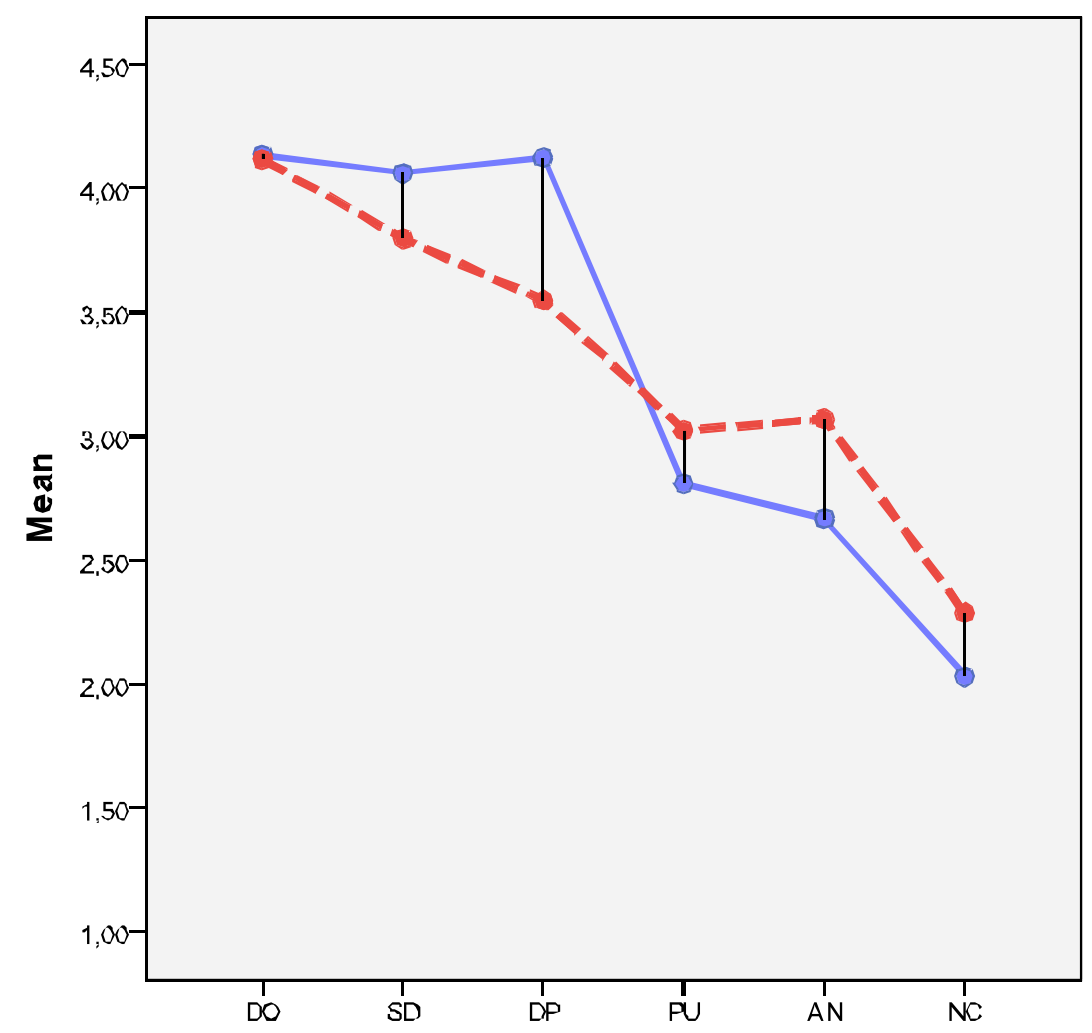

Fig. (4). Justification of aggression for each situation by sex (continuous blue line = Male; discontinuous red line $=$ Female).

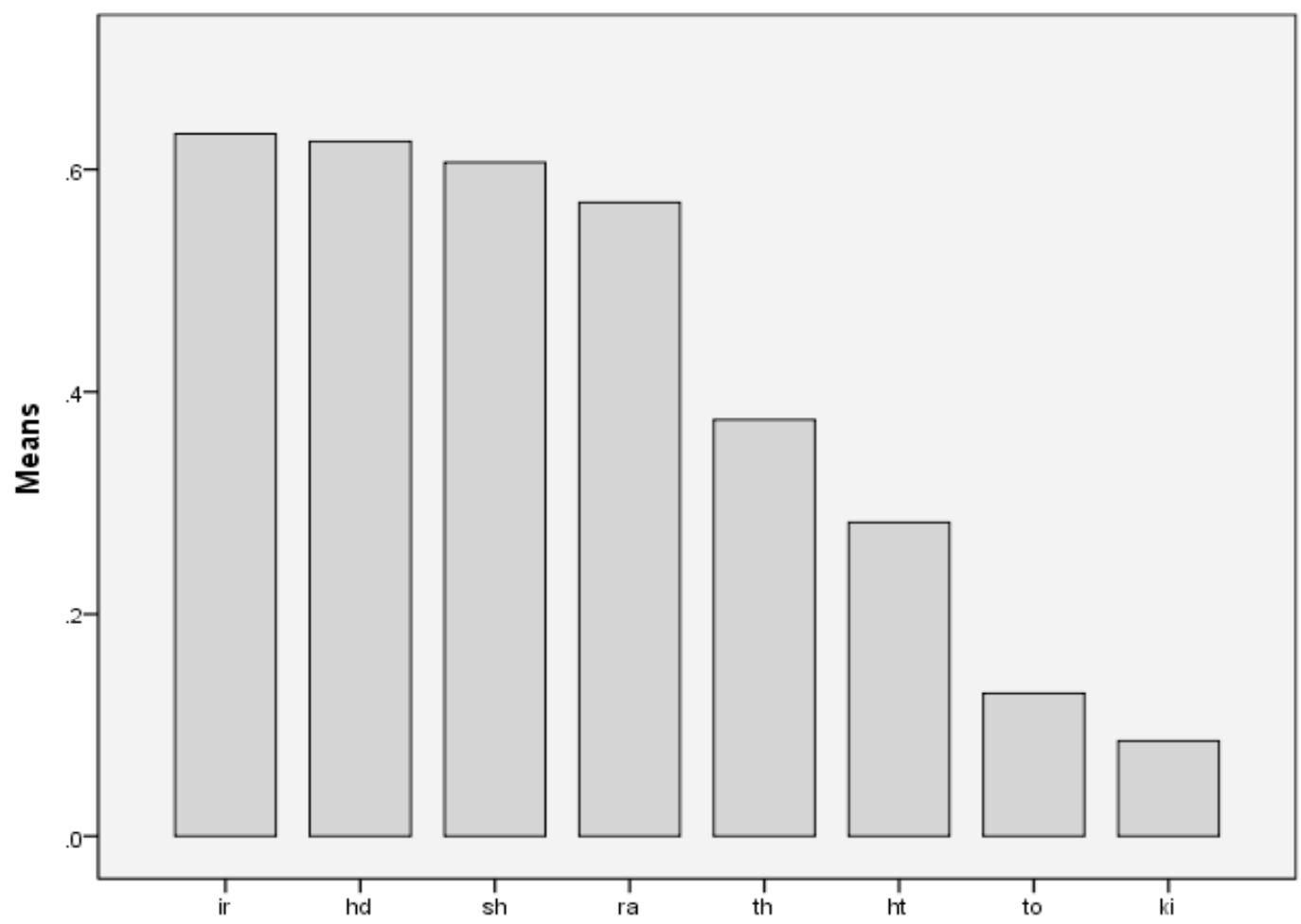

Fig. (5). Justification of different aggressive acts.

There was also a significant interaction between the justification of different aggressive acts and sexes $F(7,2261)=$ $8,717(\mathrm{p}<0.001)$. Women were more open to milder forms of aggression and found severe aggression less acceptable, as compared to men (Fig. 7). 


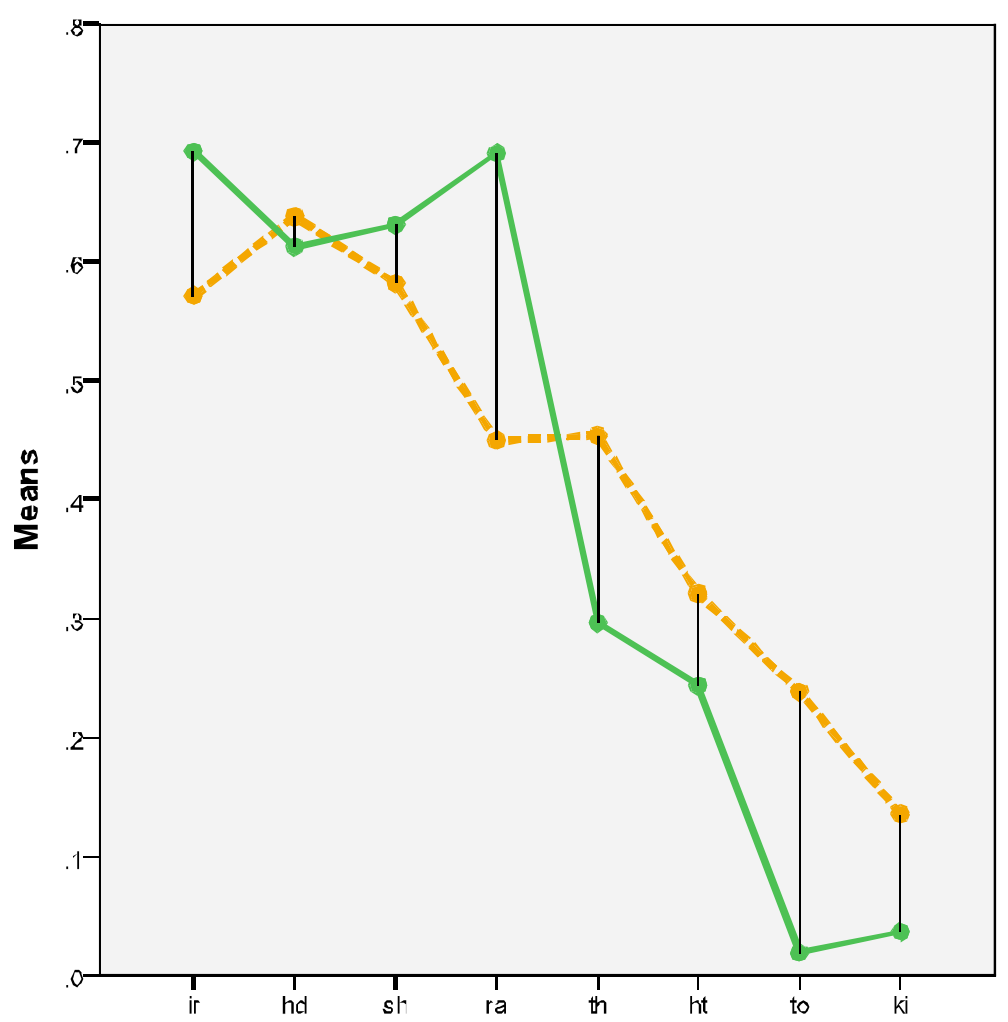

Fig. (6). Justification of different aggressive acts by countries (continuous green line = Spain; discontinuous orange line $=$ Hong Kong).

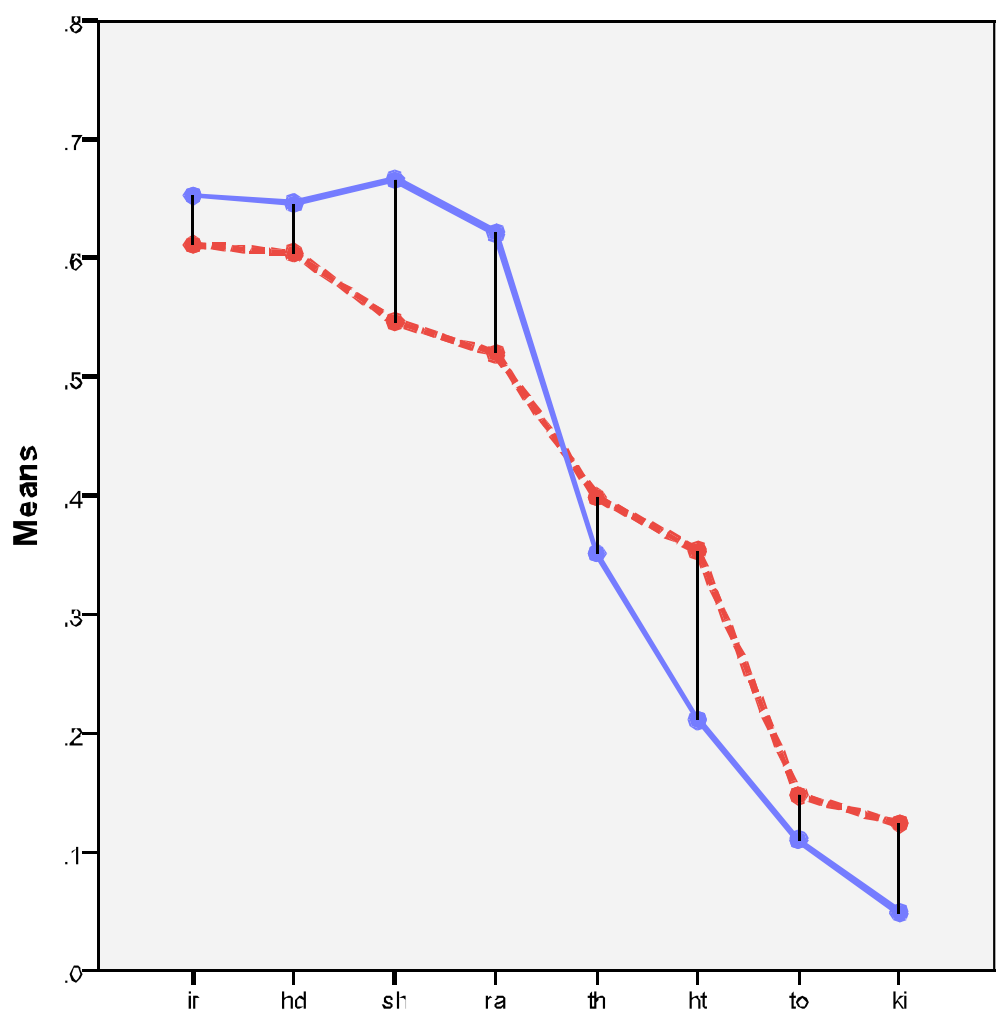

Fig. (7). Justification of aggression for each ACT by sex (continuous blue line = Male; discontinuous red line = Female).

\section{DISCUSSION}

The results showed a high consistency in the level of approval of interpersonal aggression in both samples studied.
Trends among people of such contrasting cultures were quite similar. For instance, certain acts were never justified, regardless of cultural context, and serious aggression was 
always less accepted than mild aggression [43]. These overall similarities in moral approval for aggression by people of different societies suggest a sharing of similar standards of approval, as if there were some common moral code ruling their justification. Depending upon the situation, some behaviors appear to be considered admissible by most people. In a favorable atmosphere, for instance, people engage in aggression more frequently and with greater intensity than in situations in which there is a predominance of common disapproval [15]. Therefore, the hypothesis $\mathrm{H}_{1 \mathrm{a}}$ was supported.

The finding of a bifactorial model highlights the potential importance of differentiating between different motivations for aggression in order to obtain a clearer understanding of the etiology of aggression [13]. People obstructed from reaching a desired goal may become aggressive when the obstacle is thought illegitimate or arbitrary. Even justified, reasonable, and legitimate frustrations, "for which excusable reasons exist", can activate an instigation to aggression $[46,47]$. High justification may be also expected in cases of a personal attack, such as self-defense and defense of others, as it has been shown in the present research. Consequently, $\mathrm{H}_{1 \mathrm{~b}}$ was also corroborated: there is a higher willingness of instrumental aggression than of hostile or emotional aggression [43].

These biological roots of morality, however, do not preclude certain cultural differences on judgments about aggression. Each society has a code, written or not, about acceptance or justification of different forms of aggression in specific circumstances. Prevailing cultural norms and role expectations in any given society influence what is judged to be healthy self-assertion. We should not dismiss that culture may also have a significant effect on the acceptance of aggressive acts, influencing on some attitudes toward aggression, even if others do not change. Following $\mathrm{H}_{2}$, therefore, some minor characteristics peculiar to each cultural group would also be expected.

There are several consistencies between some of the present data and what has been previously described in the literature. For instance, the higher acceptance by Spaniards of aggressive acts related to emotion, such as rage and shouting, a typically feminine stereotype (females approve more of emotional reasons), is congruent with their low masculinity score previously found $(19,33$. But, at the same time, Spaniards' justification of aggression in situations motivated by emotion, such as communication problems, is relatively low as compared to Hong Kong students. Also, a more striking departure from expectation is the relatively high justification of physical aggression among Hong Kong students. In fact, previous cross-cultural studies [25, 36, 4851] have found that Asian youth are less likely to engage in physical aggression, misconduct, and problem behavior than western youth. One explanation may be that western cultures, characterized by an individualistic orientation, are more conducive to acting out behaviors (i.e., expressing deviance) compared with cultures with a more collectivistic orientation such as Chinese [42]. This is also what has been previously observed in Beijing [36] and in Hong Kong [29]: those girls who adopted more individualistic, western values were more likely to engage in more misconduct and adolescent aggression, whereas collectivism was negatively related to their use of overt and relational aggression.

Finally $\mathrm{H}_{3}$ was also corroborated. Even if both sexes may be equally aggressive, in a quantitative way, some qualitative preferences have been observed in the present research: physical aggression was more accepted among men whereas, following the above mentioned typically feminine stereotype, women approved more than men those aggressive acts closely related to emotions, like ra or sh, and showed a higher justification of aggression in emotionally motivated circumstances, such as due to communication problems.

Generalizing the present results with undergraduate students to other less educated populations may pose some problems. Overt expressions of anger are clearly not something observed very often in normal university students; they score low on questionnaires dealing with the frequency of overt aggression and angry and aggressive dispositions. Future studies need to be replicated in other educational levels, professional backgrounds, and ages, because subpopulations defined in terms other than geography may also have different codes for the acceptance of aggression $[52,53]$. For instance, presumably consciousness objectors would show a much lower justification of violence than policemen or prisoners.

The utilization of self-reports has often been criticized because they are likely to be influenced by social desirability. Actual behavior needs not conform to ideal models of conduct [54]. Subjects may give only desirable answers to the hypothetical situations described to them [47]. Our present research with the CAMA however does not focus on absolute levels of aggressive behavior, but only on the relationship between the different samples. Also, high self-awareness magnifies the correlates between self-reports and behavior $[55,56]$. A meta-analysis has found a positive correlation between aggression, measured by self-reports and personality dimensions [57]. This assures the usefulness of these instruments in the early identification of individuals with a personality prone to aggression and, consequently, in facilitating appropriate treatment [58]. Moreover, the intrinsic motivation for action may be obscure to independent observers, yet salient to the initiator. This is better measured by self-report scales, such as the CAMA, which provides a brief but reliable and valid instrument to help further in this process of understanding the heterogeneity of aggression, with its critical distinction between instrumental and emotional factors.

It is more than advisable to establish an appropriate categorisation of the different functions and aims of aggression, especially if further research is to examine the mechanisms and functions of aggression or to shed light on the diagnosis, prevention and treatment of abnormalities and lack of control. We must never forget that biology does not condemn humanity to violence (Ramírez 2010). In fact, the opposite is true: the better our knowledge of human biology, the more capable we will be of controlling violence. As the already 25 years old Seville Statement on Violence [59] concludes: "The same species who invented war is capable of inventing peace. The responsibility lies with each of us.' 


\section{CONCLUSION}

In conclusion, a comparison of results from Hong Kong and Spain shows similar but not identical levels of justification of aggressive acts in different situations with some minor cultural differences. In both populations: a) mild aggressive acts were more acceptable than serious aggression; b) provoked aggression was approved more than unprovoked aggression; c) people of both cultures were more likely to approve acts motivated by altruism than by selfishness; and d) aggression is more justified when there is an instrumental motivation than in merely emotional situations. These overall results suggest a certain universal moral code, common to all humanity, although with minor differences according to sex, culture, education, and professional background. Civilizations so far away among them as Spain and China share similar beliefs, practices, and signals, and the deep common patterns in human development. Aggressiveness is a deeply rooted attitude that overpasses cultural or national borders $[22,25,60]$. But these findings, however, do not preclude the importance of examining intracultural variations of cultural values in relation to aggression.

\section{CONFLICTS OF INTEREST}

\section{None Declared}

\section{ACKNOWLEDGEMENTS}

The paper has been written during a sabbatical year spent by the senior author at Stanford University, as a fellow of the Hoover Institution on War, Revolution and Peace. A previous version was presented at the 28th CICA on Attitudes toward Conflict and Aggression, Bodrum (Turkey), September 2009. The research was partly supported by the grant GR35/10 from Universidad Complutense Madrid. We would like to gratefully acknowledge the students who participated in this research, such as Lucia Halty, and especially the colleagues who assisted in the application of the test in different countries, as well as to Dr. Violet Cheung, who kindly offered to edit it.

\section{REFERENCES}

[1] Lagerspetz KS, Wesmman M. Moral approval of aggressive acts: a preliminary investigation. Aggr Beba 1980; 6: 119-30.

[2] Ramirez JM. Human agresión: a multifaceted phenomenon. Madrid: Centreur 2003.

[3] Bandura A. Social cognitive theory: an agentic perspectiva. Ann Rev Psicol 2001; 52: 1-26.

[4] Bandura A. Aggression: a social learning analysis. Englewood Cliffs, NJ: Prentice Hill 1973.

[5] Buss A. The psychology of aggression. New York: Wiley 1961.

[6] Feshbach S. The function of aggression and the regulation of the aggressive drive. Psychol Rev 1964; 71: 257-72.

[7] Dodge K. The structure and function of reactive and proactive agresión. In: Pepler D, Rubin K, Eds. The development and treatment of childhood aggression. Hillsdale, NJ: Erlbaum 1991; pp 201-18.

[8] Dodge K, Coie J. Social information-processing factors in reactive and proactive aggression in children's pear groups. J Person Soc Psychol 1987; 53: 1146-58.

[9] Barratt ES, Felthous AR. Impulsive versus premeditated aggression: implications for mens rea decisions. Behav Sci Law 2003; 21(5): 619-30.

[10] Coccaro EF, Siever LJ, Klar HM, et al. Serotonergic studies in patients with affective and personality disorders. Correlates with suicidal and impulsive aggressive behaviour. Archiv Gen Psychiatr 1989; 46(7): 587-99.

[11] Linnoila M, Virkkunen M, Scheinin M, Nuutila A, Rimon R, Andgoodwin FK. Low cerebrospinal fluid 5- hydroxyindoleacetic acid concentration differentiates impulsive from non impulsive violent behavior. Life Sci 1983; 33(26): 2609-14.

[12] Ramirez JM. Some dichotomous classifications of aggression according to its function. J Organ Transform Soc Change 2009; 6(2): 85-101.

[13] Ramirez JM. The usefulness of categorizing aggression according its function. Int Soc Sci J 2010; 61(200): 65-74.

[14] Anderson CA. Effects of violent movies and trait hostility on hostile feelings and aggressive thoughts. Aggr Behav1997; 23: 161-78.

[15] Ramirez JM. Agresión. Un enfoque psicobiológico. Valencia: Promolibro 1996.

[16] Wann D, Haynes G, McLean B, Pullen P. Sport team identification and willingness to consider anonymous acts of hostile aggression. Aggr Behav 2003; 29: 406-13.

[17] Fraçzek A. Moral approval of aggressive acts: a Polish-Finish comparative study. J Cross-Cult Psicol 1985; 16: 41- 54.

[18] Fraçzek A, Ramirez JM, Torchalska B. Attitudes toward interpersonal aggression. In: LeMoli F, Ed. Multidisciplinary approach to conflict and appeasement in animals and man. Parma: Instituto di Zoologia 1985; pp. 182.

[19] Fujihara T, Kohyama T, Andreu JM, Ramirez JM. Justification of interpersonal aggression in Japanese, American, and Spanish students. Aggr Behav 1999; 25: 185-95.

[20] Musazadeh, Z. Agresión y su justificación: un estudio comparado de estudiantes iraníes y españoles. Doctoral Dissertation. Madrid, Universidad Complutense 1999.

[21] Ramirez JM. Comparison of the degree to which aggression is acceptable in four Spanish regions. Paper presented at the 7 th Biennial Meeting of ISRA, Chicago 1986.

[22] Ramirez JM. Similarities in attitudes toward interpersonal aggression in Finland, Poland, and Spain. J Soc Psicol 1991; 131: 737-39.

[23] Ramirez JM. Acceptability of aggression in four Spanish regions and a comparison with other European countries. Aggr Behav 1993; 19: 185-197.

[24] Ramirez JM. Moral approval of aggressive acts by urban students. A cross-national study on four continents. In: Ramírez JM, Richarson DS, Eds. Cross-Cultural approaches to aggression and reconciliation. Huntington NY.: Nova Science Publishers Inc 2001; pp 61-71.

[25] Ramirez JM. Justification of aggression in several Asian and European countries with different religious and cultural background. Int J Behav Dev 2007; 31(1), Serial No. 51: 9-15

[26] Lansford JE, Skinner AT. Relational and physical aggression in nine countries. Presented at the SRCD 2011 Biennial Meeting, Montreal, April 2011.

[27] Markus, HR, Kitayama S. Culture and the self: Implications for cognition, emotion, and motivation. Psychological Review, 1991; 98: 224-253.

[28] Markus, HR, Kitayama S. Culture and the self: Implications for cognition, emotion, and motivation. In: Baumeister RF (Ed.) The self in social psychology. Psychological Press 1999; pp 339-371.

[29] Cheung-Bluden VL. When East Meets West: Understanding the Misconduct of Youths in Hong Kong girls. Open Psychol J (in press).

[30] Heinrich J, Heine N. Westerners vs. the World: we are the WEIRD ones. National Post, August 21, 2010.

[31] Redfield R, Linton R, Herskovits MT. Memorandum for the study of acculturation. Am Anthropol 1926; 38: 149-52.

[32] Cheung-Bluden VL, Juang LP. Expanding acculturation theory: Are acculturation models and the adaptiveness of acculturation strategies generalizable in a colonial context? Int J Behav Develop 2008; 32(1): 21-33.

[33] Hofstede G. Gender Stereotypes and Partner Preferences of Asian Women in Masculine and Feminine Cultures. J Cross-Cult Psychol 1996; 27(5): 533-46.

[34] Hofstede G. Culture's consequences: Comparing values, behaviours, institutions, and organizations across nations. Thousand Oaks, CA: Sage Publications 2001. 
[35] Gudykunst WB, San Antonio P. Approaches to the study of communication in in Japan and the United States. In: Gudykunst WB Ed. Communication in Japan and the United States. Albany: State University of New York Press 1993; pp. 18-47.

[36] Li Y, Wang M, Wang C, Shi J. Individualism, collectivism, and chinese adolescents' aggression: intracultural variations. Aggr Behav 2010; 36:187-94

[37] Björkqvist K, Lagerspetz KMJ, Kaukiainen A. Do girls manipulate and boys fight? Developmental trends in regard to direct and indirect aggression. Aggr Behav 1992; 18: 117-27

[38] Björkqvist K. Sex differences in physical, verbal and indirect aggression: a review of recent research. Sex Roles 1994; 30: 177-88.

[39] Schober G, Björkqvist K, Somppi S. Identifying a new subcategory of aggression: sex differences in direct non-verbal aggression. J Conflict Peace Res 2009; 1: 58-70

[40] Forrest S, Eatough V, Shevlin M. Measuring adult and indirect aggression: the development and psychometric assessment if the indirect aggression scales. Aggr Behav 2005; 31(1): 84-97.

[41] Green LR, Richardson DR, Lago T. How do friendship, indirect and direct aggression relate? Aggr Behav 1996; 22(2): 81-86

[42] Richardson DR, Green LR. Social Section and threat exploration of gender effects on direct and indirect aggression. Aggr Behavior 1999; 25(6): 425-434

[43] Wann DL, Schrader MP, Adamson DR. The cognitive and somatic anxiety of sport spectators. J Sport Behav 1998; 21(3): 322-37.

[44] Ramirez JM, Andreu JM. Aggression, and some related psychological constructs (anger, hostility, and impulsivity); some comments from a research project. Neurosci Biobehav Rev 2006; 30: $276-91$

[45] Andreu JM, Ramirez JM, Raine A. Un modelo dicotómico de agresión y su evaluación mediante dos autoinformes: el CAMA y el RPQ, Psicopatología Clínica, Legal y Forense 2006; 5: 25-42.

[46] Dollar J, Doob LW, Miller NE, Mowrer OH, Sears RR. Frustration and aggression. New Haven, Connecticut: Yale University Press 1939.

[47] Berkowitz L. Frustration-aggression hypothesis: Examination and reformulation. Psychol Bull 1989; 106: 59-73

[48] Feldman SS, Rosenthal DA, Mont-Reynaud R, Leung K, Lau S. Ain't misbehavin': Adolescent values and family environments as correlates of misconduct in Australia, Hong Kong, and the United States. J Res Adoles 1991; 1(2): 109-34.

[49] Greenberger E, Chen C, Beam M, Wang SM, Dong Q. The perceivedsocial contexts of adolescents' misconduct: A comparative study of youths in three cultures. J Res Adoles 2000; 10(3): 365-88.

[50] Jessor R, Turbin MS, Costa FM, Dong Q, Zhang H, Wang C. Adolescent problem behavior in China and the United States: A crossnational study of psychosocial protective factors. J Res Adoles 2003; 13(3): 260-329.

[51] Weisz JR, Chaiyasit W, Weiss B, Eastman KL, Jackson EW. A multimethod study of problem behavior among Thai and American children in school: Teacher reports versus direct observations. Child Develop 1995; 66: 402-15.

[52] Lagerspetz KMJ, Björkqvist K, Björkqvist H, Lundman H. Moral approval of aggression and sex role identity in officer trainees, conscientious objectors to military service, and in a female reference group. Aggr Behav 1988; 14, 303-313.

[53] Millana L, Ramirez JM. Justification of aggression in young reoffenders. Open Criminal J (in press).

[54] Cohen AK. Delinquent boys: the culture of the gang. The Free Press 1955.

[55] Scheier M, Fenigstein A. Self-awareness and physical aggression. J Exp Soc Psychol 1974; 10: 264-73.

[56] Turner CW, Layton J, Simons LS. Naturalistic studies of Aggr Behav: aggressive stimuli, victim visibility, and horn honking. J Pers Soc Psychol 1975; 31(6): 1098-107

[57] Bettencourt BA, Talley A, Benjamin AJ, Valentine J. Personality and aggressive behavior under provoking and neutral conditions: a meta-analytic review. Psychol Bull 2006; 132: 751-77.

[58] Stanford MS, Greve KW, Dickens TJ Jr. Irritability and impulsiveness: Relationship to self-reported impulsive aggression. Pers Individ Dif 1995; 19: 757-60.

[59] Adams D, Barnett SA, Bechtereva NP, et al. The Seville Statement on Violence. Cahiers du mouvement universel de la responsabilite scientifique 1986; 5: 51-59.

[60] Ramirez JM, Fujihara T. Cross-cultural study of attitudes toward interpersonal aggression. Kwansei Gakuin Daigaku Syakaigakubu Kiyou 1997; 78: 97-103.

(C) Ramírez et al.; Licensee Bentham Open.

This is an open access article licensed under the terms of the Creative Commons Attribution Non-Commercial License (http://creativecommons.org/licenses/by-nc/3.0/) which permits unrestricted, non-commercial use, distribution and reproduction in any medium, provided the work is properly cited. 